\title{
Logistics lean integration strategies: case study of Samsung Electronics LCD inbound logistics
}

\author{
Jee Young Suh ${ }^{*}$ and Yong Jin Kim ${ }^{* *}$
}

\begin{abstract}
The electronics industry is a key industry in South Korea. To improve efficiency and maintain a competitive edge in fast-paced technological age it is critical to synchronize production supply with market demand. This paper focuses on the strategies which make the "just in time" production system within the electronic supply chain. The presented case study of Samsung Electronics Thin Film Transistor-Liquid Crystal Display (TFT-LCD) Inbound Logistics provides a solid example of process integration in the areas of: packaging, transportation and information sharing. The problems faced by Samsung Electronics in the early 2000's were a direct result of an imbalance between increased traffic/demand and existing production capacity. The most detrimental of these problems caused delays in supply, shortage of space in the hub center and the bottlenecking of supply transportation. This paper demonstrates how Samsung Electronics reexamined and systematically streamlined their existing processes and how they successfully integrated "lean thinking" strategies to all areas of TFT-LCD production. As a result of the integration of these strategies, Samsung Electronics began using a line-toline packing system which focused on packing items in a group using a standardized, returnable packing system. Additionally, they opted to replace their paper invoice system for an improved transportation system through which a data could reflect flows of information and materials in real time. The integration of these strategies gave Samsung Electronics a new approach to TFT-LCD Inbound Logistics which allowed them to overcome their dilemmas and resulted in successful outcomes, decreased lead times, higher quality products and an reduction in total costs.
\end{abstract}

Keywords: TFT-LCD, Lean strategies, line-to-line packing system, case study, Samsung electronics

Submission Date: 17/04/2009 ～R Revision Date: 01/06/2009 Acceptance Date: 01/06/2009

*Graduate Student, Inha University, 253 Yonghyun-dong, Nam-Ku Incheon 402-751, Korea. E-mail: jysuh@logisall.co.kr

** Corresponding Author, Assistant Professor, Asia Pacific School of Logistics, Inha University, 253 Yonghyundong, Nam-Ku Incheon 402-751, Korea. E-mail: yongjin@inha.ac.kr. 


\section{Introduction}

\subsection{Display electronics industry environment}

Display electronics and multimedia are industries that work hand-in-hand, each driving the other either to success or failure. One such example is the recent increased customer demand in notebook computers which is a direct result in the increased popularity of wireless/LAN networks. To accommodate for specific customer multimedia demands (lightweight yet with clear display capability) TFT-LCDs became the main type of display product selected by the industry. The main components of all basic display units include: (a) liquid glass plate(s), an IC circuit system and a backlight unit. In these basic units, liquid glass plates are made through a TFT process which includes a color filtering and cell process. However, the enhanced processing of producing TFT-LCDs includes the injection of a semi-liquid material between two glass plates and uses an optic anisotropic process to indicate image information by controlling the amount of light which passes through the semi-liquid material. These changes allow TFT-LCDs to maintain a higher quality of image stabilization while also increasing the ease of handing and precision during processing.

1995 was the first year during which TFT-LCDs were mass produced. It was at this time that many Korean electronics companies made the decision to allow large scale investing in the production of these innovative and impressive screens. In 2007 alone, the export revenue generated by this new technology reached a record breaking $\$ 38.5 \mathrm{M}$. This meant that 38\% of Korea’s global market share for that year was produced by its display industry. Currently, the display industry is among the 3 major exporting industries found in Korea.

This trend has sparked worldwide competition which continues to push the increasing popularity of this industry. For example, North American and European companies (which have patents on display materials, technology or equipments) are constantly focusing on the research and development of newer and more advanced technology so that they may remain competitive. While Japanese companies (which have the largest capacity for the production of metal and equipment) discuss possible mergers with other Japanese companies in order to protect their dominance in this arena. Furthermore, Taiwanese companies (which target Korean companies as their industry rival) choose to follow the strategies of other countries while making enhancements where possible. Although China has only recently caught on to the trend, many of those who recognize the industry's potential have also started to develop TFT-LCD production line systems.

\subsection{Overview of the company}

Since 2001 Samsung Electronics has held the \#1 ranking position for maintaining the highest percentage (roughly 20\%) of the global market share. However, as the market for TFT-LCDs grows and gives way to new and more aggressive competition, there is a consistent need for Samsung to keep ahead of new technologies while maintaining the demand for reasonable pricing. 
Table 1

Ranking of the display companies in revenue

\begin{tabular}{c|c|c|c|c|c|c}
\hline \multirow{2}{*}{ ranking } & \multicolumn{3}{|c|}{ LCD } & \multicolumn{3}{c}{ PDP } \\
\cline { 2 - 7 } & company & $\begin{array}{c}\text { Revenue } \\
(\$ 100 \mathrm{M})\end{array}$ & Market share & company & $\begin{array}{c}\text { Revenue } \\
(\$ 100 \mathrm{M})\end{array}$ & market share \\
\hline \hline 1 & Samsung & 183.5 & $19.5 \%$ & Matsushita & 20.8 & $36.1 \%$ \\
2 & LG display & 153.1 & $16.3 \%$ & SDI & 14.9 & $26.0 \%$ \\
3 & AUO & 152.7 & $16.2 \%$ & LG & 14.0 & $24.3 \%$ \\
4 & SHARP & 91 & $9.7 \%$ & others & 7.8 & $13.7 \%$ \\
\hline
\end{tabular}

Source: The $9^{\text {th }}$ seminar of forecasting in the electronic industry, electronic component research, 2008.5

Samsung Electronics has four production sites based in various locations throughout Korea and China. In Korea 3 sites, 'Ki-Heung' houses the production of mobile displays, 'Cheonan' maintains PC and notebook LCD production and finally large TV LCDs are manufactured in 'Tang Jung'. For the production of medium sized LCD modules, SoJu of China was selected.

As the size of the LCD panel production became bigger and the market demand kept growing, some of serious problems have arisen. The problems were mainly about imbalance with increased traffic and existing capacity such as delay in supply due to the excessive process, shortage of space in the hub center due to keeping increased safe stocks, bottleneck of supply transportation. This problem situation is described in the aspects of packaging process, working force and warehouse, transportation and information system.

\section{Problem description}

\subsection{Packaging process}

The majority of materials used in the primary supply packaging process were boxes made of danplate or corrugated cardboard. Basically, the components produced by each of the suppliers were packed independently or 'case by case'. Afterward, they were loaded onto pallets along with piling up and wrapping. After the individual packaging, the components were moved into hub center where the exterior packaging was removed. The items where then classified and stored while waiting to be added to the assembly line (stand by). The packaging dimensions were various and complex. For example, there are 65 types of danaplate module units which were designed for packaging the back light units and 42 types which were designed for packaging the top chassis. Because of the low standardization of packaging, the carrying efficiency rate of these boxes (with 
respect to their capacity) was only $47.1 \%$. The packaging boxes were only designed to protect individual materials. Sometimes even the same materials with the same dimensions were packaged by each individual supplier using disposable materials and a different module unit.

Table 2

Previous handling process from supplier to assembly line

\begin{tabular}{c|c|c}
\hline Place & Numbers of steps & Process \\
\hline \hline Supplier & 20 & Inner packing (by individual module) \\
Transportation & 3 & moving separately \\
Hub center & 10 & Stored (3 5 days) \\
Material warehouse & 6 & Moving separately and stored \\
KIT & 8 & Moving separately and stored \\
Unpacking & 4 & Unpacking by workers \\
Transportation & 5 & Shipping in the cart \\
JIT & 5 & Stand by \\
Assembly line & 2 & Assembly components to make LCD panels \\
\hline
\end{tabular}

In order to prepare the components for the assembly line, while maintaining high levels of material quality and cleanliness, employees were required to carry out a highly involved process which includes handling the materials individually. This process included many steps which were not limited to: packaging, moving, unpacking, sampling, repacking the materials and performing regularly quality checks. Due to their disposable nature, other materials such as packaging in danplate or corrugated paper required additional handling to protect them from damage or contamination. In particular, these materials required the use of additional sub packaging materials such as filling cushion materials.

\subsection{Working force and warehouse}

At the time of this paper, the number of employees working for the Samsung LCD production line (including the employees of whole suppliers) was approximately $1.7 \mathrm{M}$. Among them, the number of workers involved with the packaging process was about 6,000. The existing packaging processes contained repetitive tasks which required intensive labor and time. In addition, excessive and repetitive packaging increased the risk of component damage and/or contamination. The existing system for material warehousing was composed of hub center and material storage. The storage area was divided as follows: 39,762 $\mathrm{m}^{2}$ for shipment in the KIT room, 95, $700 \mathrm{~m}^{2}$ for third party or partner company work space and $19,800 \mathrm{~m}^{2}$ for operating deposit. It is projected that as production traffic grows the area required will rapidly exceed the existing space allotted. 


\subsection{Transportation and information system}

Each supplier used an individual transportation system based on their delivery order. The materials would then be stored in the hub center and/or the material warehouse as stock for 3 7 days. Then, before inputting the materials into the assembly line, they would then be placed in "stand-by" for 1 2 days. Due to the various modules of packaging units, the loading efficiency rate was approximately $47 \%$. This low efficiency rate, eventually led to increased transportation and storage costs. It was impossible to carry 2 loading layers in the truck. The operating cost of hub center was 300M won per year. Order and delivery data was managed by a paper invoice checking system which could be incorrect due to human error. This paper checking system could not provide real time information. Therefore, it was difficult to link real time material flows with the LCD components supply chain.

\section{Lean strategies}

The conventional method was independent and individual packaging. The lean approach for process integration focused on two target issues: one was the standardization of packaging and the other was the integration of the transportation system and information. The solution for packaging was to implement a line-to-line supply chain using standard packaging tools. The integration of the transportation required an allocation of a new transportation mode so that real time data could meet the real time flows of materials.

\subsection{Standardization of packaging}

Table 3

Integration of packaging process

\begin{tabular}{|c|c|c|}
\hline & AS-IS & TO-BE \\
\hline $\begin{array}{c}\text { Packaging } \\
\text { process }\end{array}$ & $\begin{array}{l}\text { inner packaging } \\
\text { outer packaging } \\
\text { palletizing } \\
\text { wrapping } \\
\text { un-wrapping } \\
\text { putting in the danplate box } \\
\text { outer un-packing } \\
\text { inner unpacking } \\
\text { putting in the cart } \\
\text { assembly line }\end{array}$ & $\begin{array}{l}\text { putting in the tray } \\
\text { putting in the cart } \\
\text { wrapping } \\
\text { un-wrapping } \\
\text { assembly line }\end{array}$ \\
\hline
\end{tabular}


First of all, it is important to find standard packaging module by grouping according to the common dimension or similar shape. Next, based on the module unit, the lean approach for packaging system is made. The system is composed of standardized containers such as trays and carts. Trays replaced inner packaging, while carts replaced outer packaging. This tray \& cart packaging system made line-to line (direct supply) possible. Standard packaging system increased carrying efficiency rate and made it possible that suppliers could use containers repeatedly and collectively. Reduction of packaging steps from 10 steps to 5 steps meant rapid handling, less work force, easy to keep product's quality and cleanliness.

\begin{tabular}{|c|c|c|c|}
\hline \multirow{2}{*}{$\begin{array}{c}\text { Material } \\
\text { (LCD component) }\end{array}$} & \multicolumn{3}{|c|}{ Container } \\
\hline Back light unit & Tray & & Cart \\
\hline \multirow{2}{*}{ Top chassis } & & & \\
\hline & & & \\
\hline
\end{tabular}

Figure 1. Reusable packaging containers designed for LCD module unit

In addition to the above improvements, the implementation of standardization also reduced and streamlined the packaging of BLU (Back Light Unit) and T/C(Top Chassis) and increased the carrying efficiency rate from $47 \%$ to $89 \%$. 


\subsection{Integration of transportation system}

Another strategy used by Samsung Electronics was to move the transportation system from a process involving individual supply transport to one that used a 'milk-run' or collective allocation transport system. They also implemented an integrated information system which included the automatic scheduling of allocation and real time PDA tracking which allowed real time data to reflect and meet the real time flow of materials. The integration of these steps allowed room for two key improvements in the transportation system.

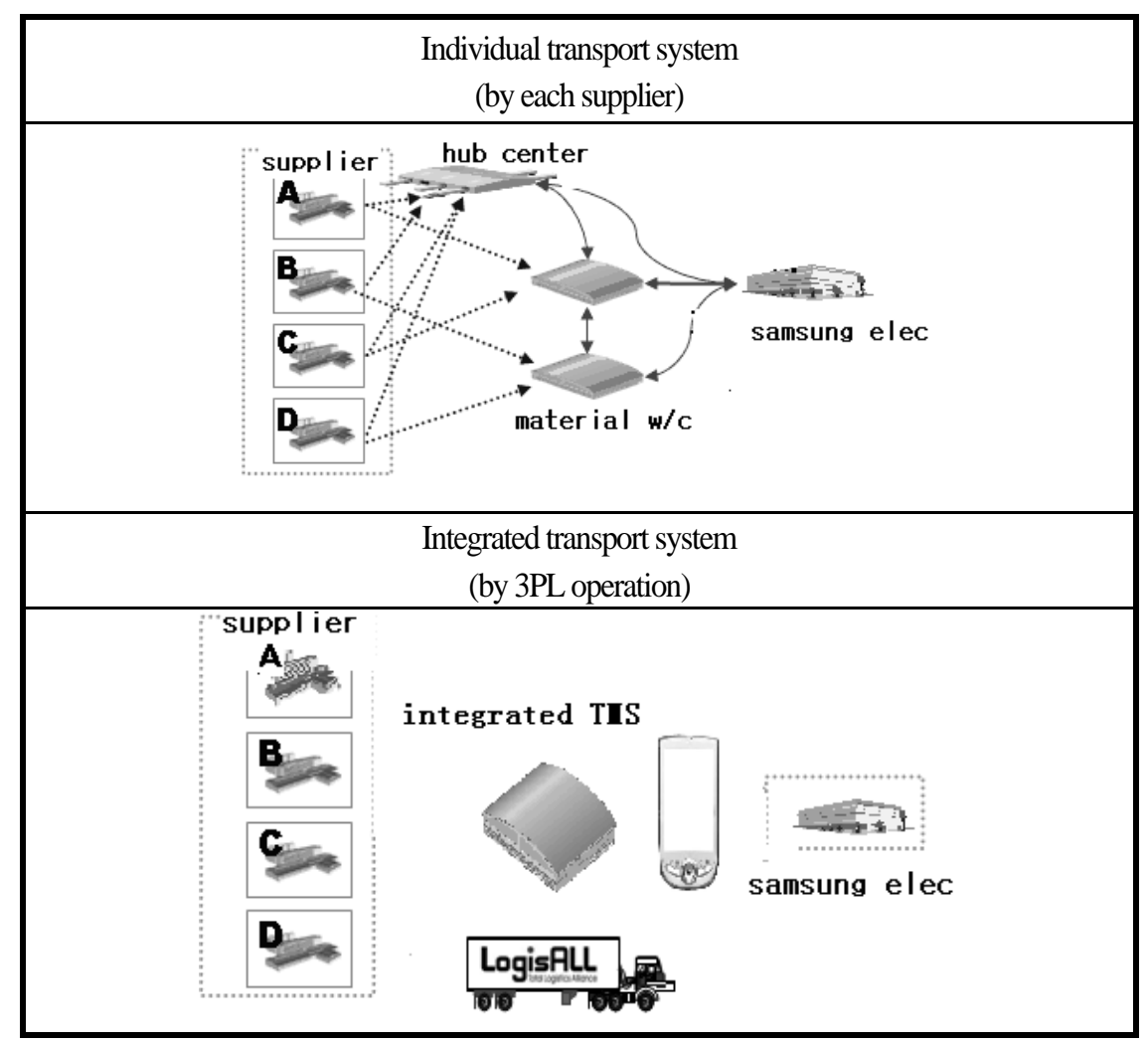

Figure 2. Integration of transport system

Primarily, the system integration reduced the dependency on expert drivers so that general drivers could accomplish the same tasks with similar efficiency. Secondarily, the use of TMS (Transportation Management System) improved visibility and communication between drivers and dispatchers which increased the ability to respond to sudden needs of shippers and reduced the possibility of potential problems while increasing shipper satisfaction. 


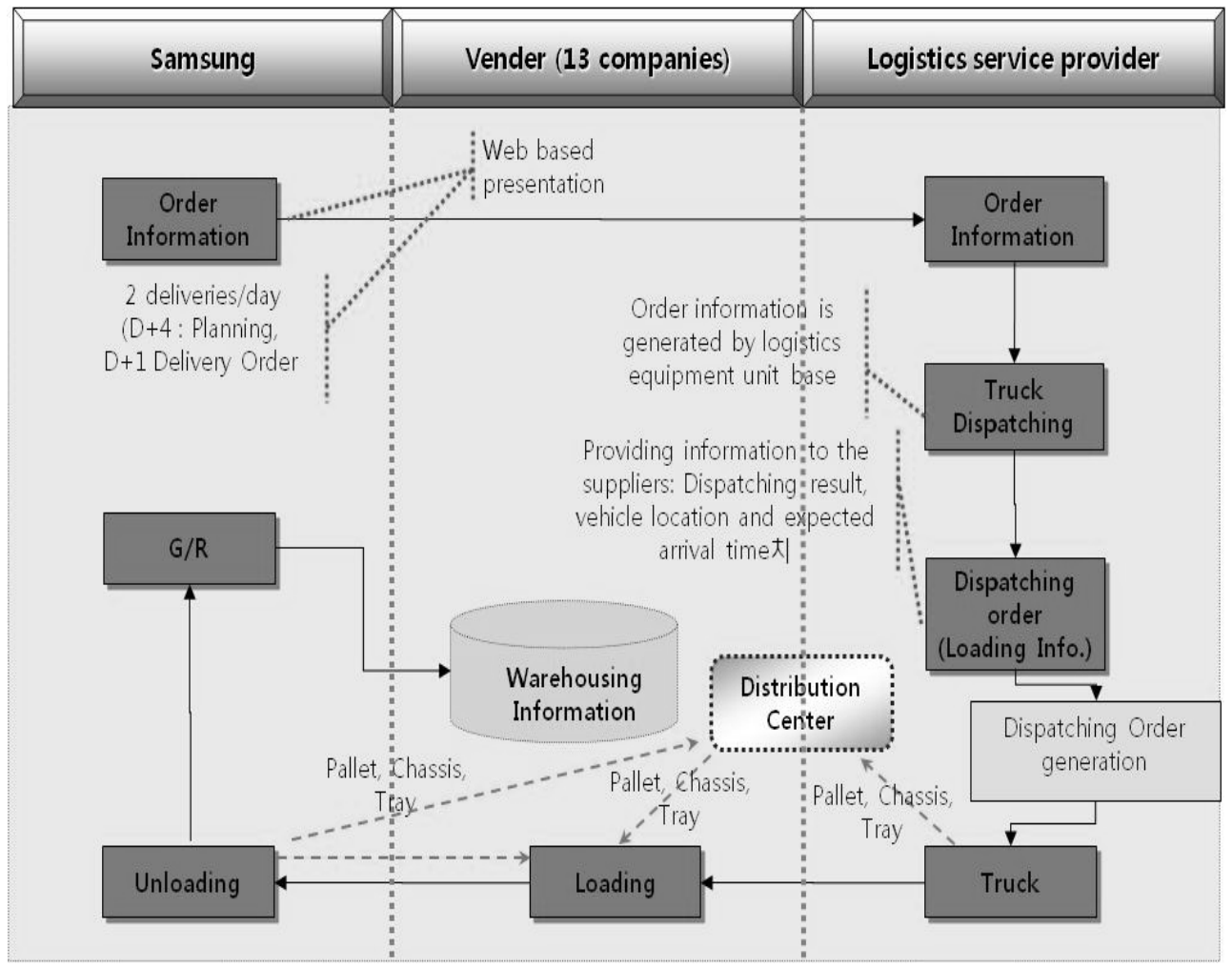

Figure 3. TMS operating process

\section{Lean strategies achievements}

\subsection{Quantitative effects}

As shown in the following table, due to the improved standardization process, the types of packaging modules were reduced by $96 \%$ and the steps involved in packaging and handling were reduced by $45 \%$. Also, the number of employees required to support the handling process was reduced by $50 \%$. As a result, the packaging costs were reduced by $64 \%$. The integrated transportation system reduced the lead time from order to delivery by $70 \%$ which reduced the area used by the warehousing of good to be reduced by $76 \%$. Finally, the number trucks required to deliver the goods was reduced by $41 \%$. 


\begin{tabular}{|c|c|}
\hline Index & Lean strategy achievement \\
\hline packaging module & $96 \%$ down \\
\hline handling steps & $45 \%$ down \\
\hline workers & $50 \%$ down \\
\hline packaging cost & $64 \%$ down \\
\hline trucks & $41 \%$ down \\
\hline Warehouse area & $76 \%$ down \\
\hline
\end{tabular}

Figure 4. Quantitative effects

\subsection{Qualitative effects}

As this example shows, Samsung Electronics was able to use 'lean strategies' such as the standardization of packaging and integration of transportation systems to regain control and efficiency by matching their production capacity with supplier transportation capacity. This integration focused on producing the right amount product at the right time with less cost which allowed both the suppliers and Samsung to share the utilization of packaging modules which allowed both to increase their buying power through a cooperative buying approach. Furthermore, it became possible for suppliers to share material information in real time. As a result, Samsung Electronics was able to produce LCD final panels in 3 days.

\section{Conclusion}

This research analyzed the methodology of process integration as it relates to: packaging, transportation and information. Samsung Electronics examined their previously existing processes from a logistical point of view. They then applied 'lean strategies' to all areas of the integration process to allow for a successful transition. Consequently, they turned away from using an individual packing and unpacking system and began using a line-to-line system which focused on a standardized, returnable packaging process. They also improved their conventional paper invoice transportation system such that it became an integrated process which could reflect actual flows of materials in real time. This approach allowed Samsung Electronics to decrease the amount of lead time and provide a guarantee of higher quality products while reducing their overall costs. Through the implementation and integration of these 'lean strategies'; Samsung Electronics is now 
able to maintain a dominant/leader ship position in many global markets. This is directly a result of the company's ability to streamline and improve their supply chain system in the area of LCD production advancing their production supply to meet market demand in only 3 day's time.

\section{Acknowledgment}

This work was supported by the Korea Research Foundation Grant funded by the Korean Government(MOEHRD) (KRF-2008-005-J01601).

\section{References}

Biz, R. D. 2005. Trend of display component in Korea. Electronic Component Research.

Displaybank. 2008. Supply chain analysis: TFT LCD component and material industry. 1-38.

Hybus. 2008. Flat Panel Display. 13-14.

Joo, D. Y. 2008. Prospect and task in display industry. KIET.

Kim, J. Y. 2005. The competition in the LCD clusters. SERI Economy Focus. 57: 1-24.

Kwon, S. K. 2006. Trend of display industry. Electronic Component Research.

Lee, B. J. 2006. Trend of major display products and industry. Electronic Component Research.

McGinnis, M.A., Boltic, S.K., and C.M. Kochunny. 1994. Trends in Logistics Thought: An Empirical Study. Journal of Business Logistics. 15(2): 273-303.

Moon, D. K. 2008. Trend and prospect of display industry. Soon Chun Hyang University.

Razzaque, M.A. and C.C. Sheng. 1998. Outsourcing of Logistics Functions: A Literature survey. International Journal of Physical Distribution and Logistics Management. 28(2): 89107.

Sheffi, Y. 1990. Third-party Logistics : Present and Futuer Prospects. Journal of Business Logistics. 11(2): 27-39.

Tarn J.M., Yen D.C., and Beaumont M. 2002. Exploring the Rationales for ERP and SCM Integration. Industrial Management \& Data Systems. 102(1): 26-34. 